Aleš Novak

Pravna fakulteta

Ljubljana

\title{
PRAVNI VIDIKI ZAKONSKE ZVEZE V RIMSKEM PRAVU
}

\section{UVOD}

Družinsko pravo, kamor ureditev zakonske zveze sodi, je del rimskega prava, ki je imel na današnje evropsko pravo relativno manj vpliva kot na primer civilno pravo. Zato se morda zdi ukvarjanje s tem manj zanimivo. Razloga, da je prav ta tema zame še vedno vredna obravnave, sta dva.

Zakonska zveza, čeprav bistveno spremenjena, obstaja še danes. Razlikujejo se pravna pravila, ki jo urejajo, razlikujejo se moralni temelji, na katerih stoji, in okolje, $\mathrm{v}$ katerega je umeščena, kot družbena institucija pa monogamna skupnost obstaja neprekinjeno vse od časov rimske države. $Z$ njo se srečujemo še danes in se bomo bržčas tudi v prihodnosti. Vedenje o preteklosti pa nam, če ne drugega, vrže novo luč na znan pojav ali kot na začetku svoje razprave "Prepoved incesta in njeni izviri" pove Emil Durkheim" : "Če hočemo dobro razumeti kakšno praktiko ali institucijo, pravno ali nravstveno pravilo, se moramo, kolikor je le mogoče, približati njenim izvirom; med tem, kar je zdaj, in tistim, kar je bilo nekoč, je namreč tesna povezava." Drugi razlog je cista in preprosta radovednost. Zanimivo je vedeti, kako so v starem Rimu pravno regulirali tako pomembno področje njihovega življenja, kakšen, če sploh, je bil vpliv takega reguliranja in kako je življenje samo vplivalo na norme.

Pravo zna namreč, $v$ nasprotju $z$ žal splošnim prepričanjem, pripovedovati zgodbe, ki so pogosto bolj ali pa vsaj enako zanimive kot zapisi zgodovinarjev in pesnikov. Zgodbe, ki jih pripoveduje pravo, so zgodbe iz resničnega življenja, celota vsakdanjih majhnih dogodkov, $\mathrm{ki}$ so morda $\mathrm{z}$ zgodovinskega vidika smešno nepomembni. Oknutni čevljar, ki vajenca s kopitom tako hudo udari po tilniku, da mu izlije oko ${ }^{2}$, pralec, ki so mu miši požrle obleke, ki jih je vzel v pranje ${ }^{3}$, rokoborec, ki je drugega ubil pri urjenju ${ }^{4}$ in brivec, ki je prerezal grlo sužnju, ki ga je bril, ker je nekdo vanj močno vrgel žogo ${ }^{5}$ morda res niso tako imenitni sopotniki za potep skozi zgodovino antičnega Rima, kot so Cezar, Cicero ali Sula, so pa morda nekoliko bolj "resnični in živi".

Seveda se je potrebno zavedati tudi meja, ki jih takšno "branje" prava ima. Motimo se lahko prav toliko, kot se bo motil učenjak, ki bo čez dva tisoč let vzel v roke na primer Zakon o varnosti $v$ cestnem prometu in se začudil nad umno in vzorno ureditvijo prometa $\mathrm{v}$, recimo, Ljubljani.

\footnotetext{
${ }^{1}$ E. Durkheim: Samomor, Prepoved incesta in njeni izviri, Studia humanitatis, SKUC, FF, Ljubljana 1992 (prevedla Braco Rotar in Rastko Mocnik), p.77.

${ }^{2}$ D. $19,2,13,4$.

${ }^{3}$ D. $19,2,13,6$.

${ }^{4}$ D. $9,2,7,4$.

${ }^{5}$ D. $9,2,11$.
} 


\section{POJEM ZAKONSKE ZVEZE}

$\mathrm{Za}$ obstoj zakonske zveze sta morala biti po rimskem pravu podana dva pogoja.

Prvi pogoj je skupno življenje; gre za objektivni pogoj. Veljalo je, da pride nevesta ob poroki živet $\mathrm{k}$ ženinu. Ko nek zakon $(12,1,13)$ v Justinijanovemu kodeksu našteva posledice sklenitve zakonske zveze, pravi: "Mulieres honore maritorum erigimus, ....et domicilia mutamus". V sklopu praznovanja je prišlo do t. im. in domum deductio $^{6}$, obreda, $v$ katerem so po opravljenih poročnih obredih nevesto odpeljali na možev dom. Žena je prevzela vodenje gospodinjstva moževe hiše, postala je domina.

Drug pogoj je affectio maritalis (kot subjektivni pogoj) ${ }^{7}$. Affectio maritalis opredeljujemo kot "željo, da se zveza šteje za zakonsko zvezo " ali čustveni odnos, kjer partnerja gledata drug na drugega kot na moža in ženo" ", skratka, med partnerjema mora obstajati nek intimni odnos. Če takega odnosa ni, gre le za konkubinat ${ }^{10}$, ki seveda nima nikakršnih pravnih posledic. Duševni odnos med partnerjema je bilo dokaj težko dokazati, zato se je štelo, da je affectio maritalis obstajala, če je bila pred poroko dogovorjena zaroka (pisna ali ne), če je bila dogovorjena dota ali če so bila opravljena darovanja ante nuptias. Seveda so ugotavljanju, ali maritalis affectio obstoji ali ne, služili vsaj posredno tudi poročni obredi. Maritalis affectio je morala biti sprva podana ves čas zakonske zveze, šele kasneje je pod vplivom krščanskega učenja o nerazdružljivosti zakonske zveze prevladalo prepričanje, da mora maritalis affectio obstajati le ob sklenitvi zakonske zveze $^{\text {It }}$.

Pogoja sta morala biti izpolnjena kumulativno.

$\mathrm{V}$ virih najdemo sicer dve definiciji zakonske zveze. Prva je Modestinova (D. 23,2,1): "Nuptiae sunt coniunctio maris et feminae et consortium omnis vitae, divini et humani iuris communicatio", drugo pa najdemo v Justinijanovih Institucijah: "Nuptiae autem sive matrimonium est viri et mulieris coniunctio, individuam consuetudinem vitae continens". Obe definiciji bi bili celo $\mathrm{z}$ vidika tedanjega prava nepopolni. Poudarek je le na objektivnem dejstvu skupnega življenja.

V rimskem pravu je veljala svoboda sklepanja zakonskih zvez: matrimonia libera esse debent (CJ. 8,38,2). Zakonska zveza načeloma temelji na soglasju ${ }^{12}$. To načelo je imelo za posledico, da morebitna zaročna obljuba ni bila iztožljiva in da prav tako ni bilo mogoče iztožiti pogodbene kazni, določene za primer, da do poroke ne pride. Šele v postklasični dobi (300 n.št. - 565 n.št.) se pod vzhodnim vplivom, morda tudi pod vplivom krščanstva ${ }^{13}$, pojavi naziranje, da zaroka ustvarja določeno obveznost. Ob zaroki je moral ženin položiti zaročno aro (arrha sponsalicia), vsoto, ki jo je izgubil, če je od zaroke odstopil. Če je od zaroke odstopila nasprotna stran, je morala aro vrniti, navadno $\mathrm{v}$ dvojnem znesku ${ }^{14}$.

\footnotetext{
${ }^{6}$ Več o samem obredu v knjigi Antiðni Rim (V. A. Ruiz et al.), MK, Ljubljana, 1967, p. 54.

7 A. Romac: Rimsko pravo, IV. izdanje, Narodne novine, Zagreb 1992, p.104.

${ }^{8}$ Dragomir Stojcević: Rimsko privatno pravo, Savremena administracija, Beograd, 1983, p.87.

9 P.E.Corbett: The Roman Law of Marriage, Clarendon Press, Oxford, 1930 (reprint 1969), p.92.

10 Še več, prav affectio maritalis je differentia specifica, ki locuje zakonsko zvezo od konkubinata. P.E.Corbett: The Roman Law of Marriage, Clarendon Press, Oxford, 1930 (reprint 1969), p.92. V. Korošec, Rimsko pravo, II.del, Jože Moškrix, Ljubljana, 1969, p.369.

"A. Romac: Rimsko pravo, Narodne novine, Zagreb 1992, p. 105.

12 Nuptiae enim non concubitus, sed consensus facit (Ulp. D. 35,1,15). Nuptiae consistere non possunt, nisi consentiant omnes, ... (Paul. D. 23,2,2), ...matrimonium, quod inter invitos non contrahitur (Cels.
} 23,2,22).

13 A. Romac: Rimsko pravo, IV izdanje, Narodne novine, Zagreb 1992, p.109.

14 V. Korošec, Rimsko pravo, II.del, Jože Moškrix̌, Ljubljana, 1969, p.373. 


\section{POGOJ ZA SKLENITEV ZAKONSKE ZVEZE}

Smisel sklepanja zakonske zveze je $\mathrm{v}$ tem, da partnerja dosežeta določene pravne (ali družbene) posledice. Pravni red kot zakonsko zvezo pripozna le zvezo med osebami $z$ določenimi lastnostmi (starost, razsodnost,...). Tudi rimsko pravo določa nekatere pogoje, ki morajo biti izpolnjeni, da se zveza šteje za iustum matrimonium (uporabljata se tudi izraza matrimonium legitimum in iustae nuptiae), torej za zakonsko zvezo, v kateri se bodo rodili zakonski otroci, kjer bo partnerica pridobila npr. pravico dedovanja po partnerju in kjer bodo doseženi drugi pravni učinki zakonske zveze.

Kateri so ti pogoji, nam najbolj shematično pokaže Ulpijan:

Iustum matrimonium est, si inter eos, qui nuptias contrahunt, conubium sit, et tam masculus pubes quam femina potens sit, et utrique consentiant, si sui iuri sunt, aut etiam parentes eorum, si in potestate sunt. (Ulp., Reg. 5,2)

Ulpijan navaja torej tri pogoje: 1. conubium,

2. doraslost,

3. consensus.

\section{CONUBIUM}

Konubij je "uxoris iure ducendae facultas"; le če med zakoncema obstaja konubij, bodo otroci člani očetove družine ${ }^{15}$. Na obstoj konubija lahko vplivajo številne okoliščine.

\section{a) DRžAVLJANSTVo}

Ulpijan nadalje pove: Conubium habent cives Romani cum civibus Romanis; cum Latinis autem et peregrinis ita, si concessum sit (Ulp., Reg. 5,4). Sprva je konubij obstajal le med rimskimi državljani, sčasoma pa so Rimljani konubij posamič ali skupinsko podelili tudi Latincem in tujcem. Nekateri pisci ${ }^{16}$ menijo, da so imeli Latini prisci ${ }^{17}$ konubij že po določbah pogodbe o Latinski zvezi, vendar pa je že Mommsen zavrnil možnost, da bi bila to splošna ureditev. Latini coloniarii ${ }^{18}$ in Latini Iuniani $^{19}$ skoraj gotovo niso imeli splošno podeljenega konubija ${ }^{20}$. Vedno pa je bilo mogoče posamezni osebi podeliti pravico konubija $v$ znak posebne naklonjenosti ali hvaležností.

Tudi peregrini so pridobili konubij le s posebno podelitvijo. To velja tako za peregrine $v$ ožjem pomenu besede, kot tudi za peregrinos dediticios ${ }^{21}$.

\section{b) RED ALI STAN}

Red ali $\operatorname{stan}^{22}$ je prav tako lahko okoliščina, zaradi katere oseba nima konubija in torej ne more skleniti po rimskem pravu veljavne zakonske zveze.

15...cum conubium id efficiat, ut liberi patris condicionem sequantur (Gai 1,56).

16 Voigt: Roemische Rechtsgeschichte, 1,258 sqq. cit po P.E.Corbett: The Roman Law of Marriage, Clarendon Press, Oxford, 1930 (reprint 1969), p.25; T.J. Cornell: The Beginnings of Rome, Routledge, 1995, p. 295.

${ }^{17}$ Latini prisci so bili 㐅lani tistih latinskih občin, ki so bili z Rimom v Latinski zvezi.

${ }^{18}$ Latini coloniarii so bili člani latinskih obð̌in in revnej\$i rimski državljani, ki so se naseljevali $\mathrm{v}$ rimskih kolonijah.

${ }_{19}$ Latini Iuniani so bili osvobojenci, ki niso bili osvobojeni po pravilih ius civile, ampak na neformalen nacin.

20 P.E.Corbett: The Roman Law of Marriage, Clarendon Press, Oxford,1930 (reprint 1969), pp.25-28.

21 Peregrini dediticii so bili "qui quondam adversus populum Romanum armis susceptis pugnaverunt, deinde victi se dediderunt"(Gai, 1,14$)$ in so imeli izmed peregrinov najmanj ugoden položaj.

${ }^{22}$ Pojem red ali stan uporabljam v pomenu, kot ga je v Antixni ekonomiji (Studia humanitatis, Škuc, FF, Ljubljana 1987, pp.44sq.) opredelil Moses I. Finley, torej kot: 
ba) Sužnji nimajo konubija ${ }^{23}$. Zveza prostega moža s sužnjo ali sužnja $s$ sužnjo imenujejo rimski pravni viri contubernium ${ }^{24}$. Pravnih posledic taka zveza načeloma ni imela, $\mathrm{z}$ izjemo prepovedi poroke med otroki, ki so se $\mathrm{v}$ taki zvezi rodili in med otroki in starši ${ }^{5}$. V postklasični dobi se je pod vplivom krščanstva položaj takih zvez pričel izboljševati, saj je bila prepovedana nasilna delitev.

bb) Postavlja se vprašanje, ali so osvobojenci imeli konubij. Zdi se, da so libertini vsaj po sprejetju lex Canuleiae 1. 445 pr.n.št. to pravico pridobili, če je niso imeli že pred tem.

Odrekati jim to pravico bi pomenilo, da se med plebejci (kar so osvobojenci dejansko bili) ustvarja nerazumljiva razlika ${ }^{26}$.

bc) Plebejcem je Zakon XII plošč prepovedoval poroko $s$ članom patricijskega stanu ${ }^{27}$. Jezik; ki ga uporabljajo viri ${ }^{28}$, zbuja vtis, da je Zakonik prepoved uvedel, ne pa le potrdil obstoj običajnopravnega pravila, ki bi obstajalo že davno prej, kot trdijo starejši pisci ${ }^{29}$. Pri tem se povečini opirajo na danes preseženo hipotezo, namreč da plebejci niso bili rimski državljani ${ }^{30}$. Moderni avtorji $i^{31}$ menijo, da je bilo oblikovanje plebejskega in patricijskega reda postopno in da so patriciji šele postopno pridobili monopolen položaj v družbenem življenju. Poskus, da se patricijski stan oblikuje v dedno skupino, se kaže tudi in predvsem $v$ postopnem onemogočanju porok med patriciji in plebejci. Določba "ut ne plebei cum patribus essent $t^{32}$ ", ki jo Cicero imenuje inhumanissima lex, je povzročila, če sodimo po virih, močan revolt, ki bi bil neobičajen, če bi šlo le za uzakonitev družbene prakse. Kaže torej, da velja sprejeti stališče, da je prepoved konubija med patriciji in plebejci noviteta, ki jo je uvedel Zakonik XII plošč. Določba je bila odpravljena leta 445 pr. n. št. S Kanulejevim zakonom (lex Canuleia).

bd) Lex Iulia de maritandis ordinibus, ki ga je leta $18 \mathrm{n}$.št. sprejel Avgust kot del načrta moralne prenove družbe ${ }^{33}$, je prepovedal, da bi se senatorji in njihovi potomci do pravnukov ženili $\mathrm{z}$ osvobojenkami ter da bi se svobodno rojeni (ingenui) ženili z oporečnimi ženskami (famosae $e^{34}$ : ženske, ki so se same ali katerih starši so se ukvarjali $z$ igralskim poklicom ali prostitucijo, ki so se ukvarjale $\mathrm{z}$ zvodništvom, ki jih je osvobodil zvodnik, ženske, ki so bile obsojene v javnem postopku). Taka zakonska

1. pravno opredeljena skupina populacije,

2. ki ima formalizirane privilegije ali disprivilegije na enem ali več poljih dejavnosti in

3. je $v$ hierarhixnem odnosu do drugih redov.

${ }^{23}$ Cum servis nullum est conubium (Ulp., Reg. 5,5).

${ }^{24}$ Paul. 2,19,6.

${ }^{25}$ P.E.Corbett: The Roman Law of Marriage, Clarendon Press, Oxford,1930 (reprint 1969), p. 30.

26 Ibid., p. 34.

${ }^{27} \mathrm{O}$ možnih razlogih in ozadju sprejetja te določbe v Zakonik XII plošc T.J. Comell: The Beginnings of Rome, Routledge, 1995, p. 292.

${ }^{28}$ Cic. De re publ. 2,37,63 ter Dionysius Antiq. Rom. 10,60 in Liv. Ab urbe condita libri 4,4,5 in 4,6.

29 P.E.Corbett: The Roman Law of Marriage, Clarendon Press, Oxford,1930 (reprint 1969), p. 30. Corbett meni, da bi medsebojne poroke patricijev in plebejcev pomenile "osupljiv razkorak s siceršnjo družbeno prakso".

${ }^{30}$ Mommsen je na primer menil, da plebejci nimajo politiěnih ali pravnih pravic in so klienti, dodeljeni patricijskim gentes, Niebuhr pa, da so bili plebejci zunaj originalne skupnosti; cit. po T.J. Cornell: The

Beginnings of Rome, Routledge, 1995, p.242. Podobno je Corbettovo stališče, o.c. p. 30. Tudi Margetić meni, da plebejci niso uživali rimskega državljanstva vse do padca kraljevine; v Lujo Margetić: Neka pitanja iz najstarijeg drustvenog i politiðkog uredenja Rima, Zbornik radova Pravne fakultete u Splitu, X, 1973, p.170.

${ }^{31}$ Npr. T.J. Cornell: The Beginnings of Rome, Routledge, 1995, p. 255.

${ }^{32}$ Cic. De re publ. 2,37,63.

${ }^{33}$ Gl. Se V. Korosec: Nastanek Avgustovega principata, Zbornik znanstvenih razprav PF, 1943.

34 Ulp. Reg. 13,1-2. 
zveza ni bila neveljavna, zakon je le odtegnil določene običajne posledice zakona ${ }^{35}$. Šele Mark Avrelij je take zakonske zveze razglasil za nične ${ }^{36}$.

\section{c) SORODSTVENA ZVEZA}

Sorodstvena zveza je prav tako pomenila oviro za sklenitev veljavne zakonske zveze. Prepoved sklenitve zakonske zveze je brez izjem veljala med predniki in potomci v ravni črti (oče, mati - otroci...). V stranski črti je prepoved sprva veljala do šestega kolena. Klasično pravo je zakon prepovedal le med sorodniki $v$ drugem in tretjem kolenu. Za cesarja Klavdija je senat (1. 49) odpravil zadržek glede zakona med stricem po očetu in nečakinjo, saj se je Klavdij želel poročiti z Agripino. Konstancij in Konstans sta to izjemo 1. 342 odpravila $^{37}$.

\section{d) VOJAŠKA IN URADNIŠKA SLUŽBA}

$\mathrm{V}$ prvem in drugem stoletju našega štetja je veljalo, da vojakom zaradi vojaške discipline ni dovoljeno skleniti zakonske zveze. Dejanska skupnost vojaka z žensko je bila torej konkubinat, ki je bil lahko legaliziran šele, ko je bil vojak častno odpuščn iz vojaške službe ${ }^{38}$. Zdi se, da gre le za poostreno normo republikanske dobe, ki je vojaku prepovedovala samo živeti $z$ ženo med služenjem roka ${ }^{39}$. Določba se je prenehala uporabljati še pred koncem četrtega stoletja. Prav tako je veljalo, da se cesarski uradniki, ki opravljajo administrativne ali vojaške zadeve, ne smejo poročiti $\mathrm{z}$ žensko, ki je bila rojena ali stalno živi $\mathrm{v}$ provinci, $\mathrm{v}$ kateri opravljajo svojo dolžnost $^{40}$.

\section{DORASLOST}

Že iz same narave zakonske zveze izhaja, da morata biti partnerja vsaj dorasla. Moški mora biti pubes, ženska viripotens ${ }^{41}$. V najzgodnejšem obdobju se je doraslost ugotavljala $s$ telesnim pregledom ${ }^{42}$, kasneje se je štelo, da je deklica dosegla doraslost z 12 leti, glede dečkov pa je med sabinijansko in prokulijansko šolo nastal spor. Sabinci so vztrajali pri individualni presoji (torej telesnemu pregledu), prokulijanci pa so menili, da velja določiti štirinajsto leto kot splošno mejo za dosego doraslosti. Justinijan je sprejel prokulijansko stališče in tako dokončno odpravil, kot sam pravi ${ }^{43}$, "indecora observatio". Takšen pregled naj bi ne bil v skladu s "castitas temporum nostrorum ${ }^{44 " .}$

Naj na tem mestu še omenim, da castratus ni mogel skleniti veljavne zakonske zveze, pač pa je veljavno zvezo lahko sklenil spado.

\footnotetext{
${ }^{35}$ P.E.Corbett: The Roman Law of Marriage, Clarendon Press, Oxford, 1930 (reprint. 1969), pp. 37sq.

${ }^{36}$ V. Korošec, Rimsko pravo, Il.del, Jože Moskrič, Ljubljana, 1969, p. 371.

${ }^{37}$ V. Korošc, Rimsko pravo, II.del, Jože Moškric, Ljubljana, 1969, p. 371 in P.E.Corbett: The Roman Law of Marriage, Clarendon Press, Oxford, 1930 (reprint 1969), p. 48.

${ }_{38}$ H. Hausmaninger, W. Selb: Roemisches Privatrecht, Boehlau Verlag, Wien, Koeln, Weimar, 1991.

39 P.E.Corbett: The Roman Law of Marriage, Clarendon Press, Oxford, 1930 (reprint 1969), p. 41.

${ }^{40}$ Ibid. , p. 42

${ }^{41}$ Ulp. Reg. 5,2 in Inst. 1,10,pr.

${ }^{42}$ P.E.Corbett: The Roman Law of Marriage, Clarendon Press, Oxford, 1930 (reprint 1969), p. 51.

${ }^{43}$ C.J. $5,60,3$.

${ }^{44}$ Inst. 1,22 pr.
} 


\section{CONSENSUS}

Splošno pravilo je bilo jasno: "Nuptiae consistere non possunt nisi consentiant omnes, id est qui coeunt quorumque in potestate sunt ${ }^{45}$. Kljub pogostemu sklepanju, da je pater familias otroka, zlasti hčer, lahko oženil po svoji volji, ne da bi upošteval njeno mnenje, ni trdnih dokazov, da mu je pravo to tudi dopuščalo ali pri tem celo pomagalo. Gotovo je obstajala moralna dolžnost otroka, da uboga očetov ukaz ${ }^{46}$. Taka dolžnost je razumljiva; če upoštevamo strogo hierarhijo rimske družine in oblast, ki jo je oče imel nad svojimi otroki. Brez dvoma se je tudi pogosto dogajalo, da je sicer nezainteresirani partner pod očetovim pritiskom popustil.

\section{a) Soglasje PARTNERJEV}

Po mnenju nekaterih avtorjev je vprašljivo, ali je bilo soglasje neveste vse do 5. stoletja res potrebno ${ }^{47}$. Vsekakor je bila zakonska zveza, ki jo je katerikoli od partnerjev sklenil pod prisilo, veljavna. Zdi se, da je bilo spričo aktivne vloge, ki jo je $v$ obredih igral ženin, potrebno njegovo aktivno soglasje. Če se je sklenitvi zakonske zveze uprl; ga $k$ temu ni bilo mogoče prisiliti $z$ uporabo državnega aparata ${ }^{48}$. Vloga neveste je bila $v$ obredih bolj pasivna, zato je mogoče sklepati, da je zadostovalo že, če se zvezi ni aktivno uprla. Celzov izraz "inter invitos" ${ }^{\prime 9}$ je mogoče razumeti tudi kot dokaz, da zakonska zveza ni bila mogoča, če se je hči temu odločno uprla ${ }^{50}$.

\section{b) SOGLASJE DRUŽINSKEGA OČETA (PATER FAMILIAS)}

Soglasje družinskega očeta je bilo neobhodno potrebno. Ženin in nevesta zakonske zveze nista mogla veljavno skleniti, če s tem pater familias ni bil seznanjen ali s tem ni soglašal. Še več, če je bil ženinov pater familias njegov ded in je imel in potestate ženinovega očeta, je moral soglašati še slednji ${ }^{51}$. Takšna ureditev se razlaga s starim načelom rimskega prava: nemini invito heres suus adgnascitur; ženinov oče je tako lahko soodločal, kdo bo po njegovi smrti dedoval. Ženin je tako potreboval pozitivno soglasje. Je torej mogoče sklepati, da je za hčer zadoščalo le, da njen pater familias zvezi ni nasprotoval? Hčerina poroka za njeno družino nima nikakršnih pravnih posledic. Papinijan ${ }^{52}$ zahteva, da hčerin pater familias za poroko ve in da tudi pozna ženina. Zdi se torej, da je tudi za hčer potrebno pozitivno soglasje, čeprav je morda dano molče ${ }^{53}$.

V katerih primerih soglasje družinskega očeta ni bilo potrebno? Vsekakor soglasje družinskega očeta ni potrebno, če pade v ujetništvo ${ }^{54}$. Precej manj jasna je situacija, ko pater familias le izgine, ne ve pa se, ali je v ujetništvu. Justinijan je za oba primera določil, da mora preteči rok treh let, da se lahko sin poroči brez soglasja

${ }^{45}$ D. 23,2,2, enako Ulp. Reg. 5,2: ...Iustum matrimunium est,..., et utrique consentiant, si sui iuris sunt, aut etiam parentes eorum, si in potestate sunt.

${ }^{46}$ To dokazuje tudi Aulus Gellius $(2,7,18)$ ter Ulp., D.3,2,11,4.

${ }^{47}$ Argumenti se opirajo predvsem na možnost patris familias, da razveže zakon svoje hčere tudi proti njeni volji in pa na razliko $v$ izrazih: filiam in matrimonium dare, collocare, tradere in filium uxorem ducere pati (P.E.Corbett: The Roman Law of Marriage, Clarendon Press, Oxford, 1930 (reprint 1969), p. 55).

${ }_{48}$ C. $5,4,12$ in D. $23,2,22$.

${ }^{49}$ Gl. op. 13 .

${ }^{50}$ C. $5,4,14$ pravi, da se nihce ni prisiljen porociti, P.E.Corbett: The Roman Law of Marriage, Clarendon Press, Oxford, 1930 (reprint 1969), pp. 56sqq.

51 P.E.Corbett: The Roman Law of Marriage, Clarendon Press, Oxford, 1930 (reprint 1969), p. 57.

52 D. $23,1,7,1$

53 P.E.Corbett: The Roman Law of Marriage, Clarendon Press, Oxford, 1930 (reprint 1969), p. 59.

${ }^{54}$ D. $23,2,11$. 
družinskega očeta. Če je oče umobolen (furiosus), se lahko hči poroči brez njegovega soglasja, glede sina pa klasični pravniki niso bili enotnega mnenja ${ }^{55}$. Justinijan je končno določil, da se lahko sin poroči brez soglasja umobolnega očeta.

Če je pater familias neupravičeno odklanjal svoje soglasje, ga je hčeri namesto družinskega očeta lahko dal pretor, glede sina je to možnost uvedel šele Justinijan ${ }^{56}$.

Če je bila nevesta sui iuris, je morala za zakon cum manu pridobiti varuhovo soglasje, za zakon sine manu pa tako soglasje ni bilo potrebno ${ }^{57}$.

\section{ZAROKA}

Običajno sta bodoča zakonca pred poroko sklenila zaroko. Namen je jasen: zakonca na ta način jasno pokažeta svoj namen, skleniti zakonsko zvezo. Zgodovinsko gledano ima zaroka bolj pritlehne osnove: zaroka označuje fazo, ko sta se stranki pri kupu žene sporazumeli o kupčiji ${ }^{58}$. Sledila je dejanska menjava žene za blago ali, kasneje, denar. Sklenitev zaroke ni bila potrebna za veljavnost kasnejše zakonske zveze.

Osebi, ki sta se zaročili, nista smeli biti več infantes (preseči sta morali starost 7 let) ali infantiae proximi ${ }^{59}$. Pater familias sina ni mogel zaročiti proti njegovi volji, enako je veljalo za emancipiranega sina, položaj je mnogo manj jasen glede dekleta. Zdi se, da njeno soglasje ni bilo potrebno, da je torej pater familias hčer lahko zaročil tudi proti njeni volji ${ }^{60}$. Njen molk se je vsekakor štel za soglasje ${ }^{61}$, ugovarjala pa je lahko le, če je bil bodoči ženin "indignum moribus vel turpem ${ }^{62}$ ".

Zaroka pomeni medsebojno obljubo partnerjev ${ }^{63}$ (in družinskih očetov, pod katerih oblastjo sta), da bosta moški in ženska sklenila zakonsko zvezo. Postavlja se vprašanje, ali je takšna obljuba iztožljiva ali ne ${ }^{64}$. Mogoče je pritrditi mnenju, da je v najzgodnejši dobi taka obljuba bila iztožljiva, vse do klasične dobe (27. pr.n.št. - 300 n.št.) namreč ni zaslediti, da bi katerikoli pravni vir odrekal pravico, da se taka obveznost iztoži ${ }^{65}$. Klasično pravo je nedvoumno zavračalo tudi posredno zmanjševanje načela prostega sklepanja zarok. Rimski pravnik Paul jasno označi dogovor, da je stranka dolžna plačati določeno vsoto, če do poroke ne pride, kot dogovor "non secundum bonos mores"66, in kot tak neiztožljiv "quia inhonestum visum est vinculo poena matrimonia obstringi sive futura sive iam contracta"67.

\footnotetext{
55 Inst. 1,10, pr.

${ }^{56}$ V. Korošec, Rimsko pravo, II.del, Jože Moßkrix, Ljubljana, 1969, p. 370.

${ }^{57}$ P.E.Corbett: The Roman Law of Marriage, Clarendon Press, Oxford, 1930 (reprint 1969), p. 60.

58 Ibid., p. 1.

${ }^{59}$ Ibid., p. 2.

60 Pater familias je vsekakor lahko hcerino zaroko razdrl, ne da bi jo vprašal za mnenje (D.23,1,10) - $a$ fortiori bi torej lahko sklepali, da je zaroko lahko $v$ imenu hcere tudi sklenil.

${ }^{61}$ D. $23,1,12$.

${ }^{62}$ D. $23,1,12$.

${ }^{63}$ Sponsalia sunt mentio et repromissio nuptiarum futurarum (D. $23,1,1$ ).
}

${ }^{64}$ A. Romac na primer meni, da so takšne obljube $v$ preteklosti bile iztožljive, da pa so kasneje to lastnost izgubile (A. Romac: Rimsko pravo; IV. izdanje, Narodne novine, Zagreb 1992, p. 109), Korošec pa zagovarja stališce, da so bile zaročne obljube iztožljive le $v$ latinskih mestih, ne pa tudi $v$ Rimu, kjer je "そe od nekdaj" veljala svoboda tudi glede sklepanja zarok (V. Koroß̌c, Rimsko pravo, II.del, Jože Moskrix, Ljubljana, 1969, p. 372).

${ }^{65}$ Podobno stališe $\vee$ H. Hausmaninger, W. Selb: Roemisches Privatrecht, Boehlau Verlag, Wien, Koeln, Weimar, 1991, pp. 153sq.

${ }^{66}$ D. $45,1,134$, pr.

${ }^{67}$ D. $45,1,134$, pr. 
Kasneje je pod vzhodnjaškim vplivom zaroka pridobila več pomena. Uveljavil se je tudi običaj, da je ženin ob zaroki nevestinemu očetu ali nevesti sami dal kot zaročno aro (arrha sponsalicia) neko znatnejše darilo ${ }^{68}$. Če do poroke ni prišlo iz razlogov, ki so bili na strani ženina, je znesek are izgubil, če pa so bili razlogi na strani neveste, je lahko ženin zahteval dvojni znesek are (poleg vrednosti darila še "kazen" $v$ enakem znesku). posledice $^{69}$ :

Zanimivo je, da je rimsko pravo celo na zaroko vezalo določene pravne - če je oseba sklenila dve zaroki ali več, ali če je s poroko prekršila dogovor z drugo osebo, je imelo to za posledico, da je tako osebo zadela infamia (taka oseba zato ni mogla nastopati kot zagovornik tujih koristi pred sodiščem, ni mogla nastopati kot pravdni pooblaščenec $\mathrm{v}$ tujih pravdah ali naperiti popularnih tožb,...);

- zaroka je med zaročencema vzpostavila nekakšno svaštvo, saj se zaročenec / zaročenka ni mogel / mogla poročiti s staršem ali otrokom drugega;

- reskript Severa in Karakale dopušča, da zaročenec preganja zaročenko zaradi nezvestobe;

- zaročenec je prost kazni zaradi neporočenosti, ki jih predvideva Lex Iulia, če je zaročenka stara vsaj deset let;

- zaročenec ni dolžan pričati proti zaročenkinemu očetu et vice versa...

\section{OBLIKI ZAKONSKE ZVEZE}

Rimsko pravo je poznalo dve temeljni obliki zakonske zveze. Zakonsko zvezo cum manu, kjer je, če omenim le najznačilnejšo lastnost, žena prišla pod moževo oblast, in zakonsko zvezo sine manu, kjer je ženska ostala pod oblastjo svojega družinskega očeta (pater familias). Zgodovinsko gledano je bila zgodnejša zakonska zveza cum manu, vendar je zakonska zveza sine manu že $v$ tretjem in drugem stoletju pred našim štetjem postala prevladujoča oblika zakonske zveze.

\section{1) ZAKONSKA ZVEZA CUM MANU}

Zakonska zveza cum manu je imela za posledico, da se je ženska osvobodila očetovske oblasti svojega družinskega očeta. To hkrati pomeni, da je zapustila svojo agnatsko družino ${ }^{70}$ (agnatsko družino sestavljajo vse osebe, ki so pod patria potestas istega družinskega očeta). S tem ženska izgubi dedno pravico, ki jo ima po članih agnatske družine. Če je sui iuris in ima svoje premoženje ${ }^{7 l}$, pripade to možu. Ni ji treba več častiti kulta njenih prednikov ${ }^{72}$.

S sklenitvijo zakonske zveze cum manu ženska vstopi v moževo družino. Kot žena je pod oblastjo (manus) svojega moža, če je ta svojepraven, če pa je pod oblastjo svojega očeta, ima manus nad sinovo ženo pater familias ${ }^{73}$. Moževa oblast nad otroki je bila popolna, lahko jih je ubil ali prodal, če naj omenim le dva najizrazitejša primera obsega te oblasti ${ }^{74}$.

\footnotetext{
${ }^{68}$ V. Korołec, Rimsko pravo, II.del, Jože Moskriz, Ljubljana, 1969, p. 373.

69 Navajam po P.E.Corbett: The Roman Law of Marriage, Clarendon Press, Oxford, 1930 (reprint 1969), pp. 16sq.

70 A. Romac: Rimsko pravo, IV. izdanje, Narodne novine, Zagreb 1992, p. 111.

${ }^{71}$ Nad njo je bedel futor mulieris, ki je moral odobriti sklenitev pomembnejsih pravnih poslov.

72 P.E.Corbett: The Roman Law of Marriage, Clarendon Press, Oxford, 1930 (reprint 1969), p. 108.

73 Ibidem, p.108, v nadaljevanju bom iz razlogov smotrnosti క̌tel, da je ženin mož svojepraven, da je torej pater familias.
} 
Oblast, ki jo je imel mož nad ženo, je bila le nekoliko bolj omejena. Ženo je smel po starem civilnem pravu ubiti le $v$ dveh primerih: če jo je zalotil pri prešuštvovanju ali pri pitju vina ${ }^{75}$. To pravico moža je že zgodaj omejila določba, po kateri mora mož, preden ženo obsodi, sklicati posvetovalno telo, tako imenovano domače sodišče (iudicium domesticum), $v$ katerem sodelujejo tudi njeni krvni sorodniki $^{76}$. Ce tega ni storil, je to bržčas imelo za posledico cenzorsko kazen ${ }^{77}$. Žene prav tako ne sme prodati. Plutarh pripisuje Romulu zakon, po katerem naj bi moža zadela sacratio, če bi ženo prodal $^{78}$. Mož in žena sta si dolžna medsebojno spoštovanje (reverentia), vendar mora žena ubogati moževe razumne ukaze ${ }^{79}$.

Žena postane s poroko mater familias. Izraz se je v republikanskem Rimu uporabljal le za ženske, ki so bile v zakonu cum manu. Mater familias je imela pravico ukazovati mlajšim ženskam in otrokom ${ }^{80}$. Kot matroni ji je šlo posebno spoštovanje: v Rimu so na primer vozila smeli uporabljati le magistrati in matrone. Kot izraz spoštovanja žensk se pogosto navaja, da sta bila oba prevrata zgodnje republike (izgon kraljev in upor zoper decemvire) posledica nasilja nad žensko ${ }^{81}$.

Ženska $\mathrm{z}$ vstopom v moževo družino pridobi dedno pravico po članih njegove družine.

Kot žena se mora preseliti k možu. Če tega ne stori, lahko mož z interdiktom de uxore exhibenda vel ducenda to izsili od ženinih staršev ali drugih oseb, ki jo zadržujejo. Žena pridobi socialni status moža ${ }^{82}$.

\section{2) ZAKONSKA ZVEZA SINE MANU}

Če stopita partnerja v zakonsko zvezo sine manu, ostane žena v svoji agnatski družini in pod oblastjo (patria potestas) svojega očeta oziroma družinskega očeta. Ta je lahko dolgo časa dosegel razdor zakona.s tem, da je $\mathrm{z}$ interdiktom de liberis exhibendis et ducendis zahteval hčerko in jo odpeljal s seboj. Antonin Pij pa je omogočil možu, da zakon ohrani, če dokaže, da je složen (bene concordans) ${ }^{83}$. Žena seveda ohrani dedno pravico ob smrti članov svoje družine ${ }^{84}$. Če je ženska sui iuris, je pod varuštvom tutor-ja mulieris.

\footnotetext{
${ }^{74}$ Konstantin $\mathrm{v}$ nekem svojem ediktu iz 4 .stol.n. St. to oblast imenuje ius vitae ac necis. Seveda te pravice ne gre jemati kot izraz stalne družbene prakse. Kato je na primer dejal, da skruni najvecjo svetinjo, kdor tepe ženo ali otroka (Plut., Življenje velikih Rimljanov, CZ, Ljubljana, 1981,p. 60).

${ }^{75}$ V. Korošec, Rimsko pravo, Časopisni zavod uradni list, Ljubljana, 1991, p. 97.

${ }^{76}$ P.E.Corbett: The Roman Law of Marriage, Clarendon Press, Oxford, 1930 (reprint 1969), p. 109.

${ }^{77}$ Valerij Maksim poroča, da je bil L. Anij 1. 307. pr.n.št. izkljuð̌en iz senata, ker je ženo usmrtil, ne da bi se posvetoval z domačim sodišcem (Val. Max. Facta et dicta memorabilia 2,9,2).

${ }^{78}$ Sakracija je ena najstarejših kazenskih sankcij rimskega prava in ima moxne sakralnopravne poteze. Ker se je štelo, da je neko hudodelstvo porušilo sožitje bogov in ljudi (pax deorum), je bil storilec posvečen bogovom. To je pomenilo, da je storilca lahko kdorkoli nekaznovano ubil. Vec v: Janez Kranjc: Kaznovanje in kazni v rimskem kazenskem pravu, Zbornik znanstvenih razprav, PF, 1987.

79 P.E.Corbett: The Roman Law of Marriage, Clarendon Press, Oxford, 1930 (reprint 1969), pp. 125sq.

${ }^{80}$ Dragomir Stojłević: Rimsko privatno pravo, Savremena administracija, Beograd, 1983, p.86.

${ }^{81}$ V. Koroß̌ec, Rimsko pravo, II.del, Jože Moškrix, Ljubljana, 1969, p.375, op.28.

${ }^{82}$ Mulieres honore maritorum erigimus, genere nobilitamus et forum ex eorum persona statuimus et domicilia mutamus (C.J. 12,1,13).

${ }^{83}$ V. Korošec, Rimsko pravo, II.del, Jože Moškrix, Ljubljana, 1969, p. 375 in H. Hausmaninger, W. Selb: Roemisches Privatrecht, Boehlau Verlag, Wien, Koeln, Weimar, 1991, pp. 154sq.

${ }^{84}$ V. Korošec, Rimsko pravo, II.del, Jože Moskrič, Ljubljana, 1969, p. 375.
} 
Ženske tudi s poroko sine manu pridobijo socialni položaj moža, prav tako se preselijo $\mathrm{k}$ možu. $\mathrm{V}$ strogi terminologiji republikanskega Rima taka ženska ni bila mater familias $^{85}$. Vendar pa žena s poroko ni pridobila moževega državljanstva ${ }^{86}$.

Če je bila žena še pred poroko sui iuris, je lahko obdržala svoje premoženje ${ }^{87}$ Žena pa je bila možu dolžna zvestobo, njen mož je bil tisti, ki je odločal o vzgoji otrok. Možu je morala izkazovati spoštovanje. Čeprav je mož po črki zakona ni bil dožan preživljati, so mu to dolžnost nalagali družbeni običaji.

\section{SKLENITEV ZAKONSKE ZVEZE}

Rimsko pravo ni predpisovalo oblike sklenitve zakonske zveze. To seveda ne pomeni, da ta ni imela posledic tudi na pravnem področju. Pravo le ni določalo postopka sklenitve, ki bi moral biti upoštevan, da bi do veljavne zakonske zveze sploh prišlo. Slovesnosti, ki so sodile $\mathrm{k}$ posamezni obliki sklenitve zakonske zveze, so določali običaji in v najzgodnejšem obdobju verski predpisi.

Viri govorijo o treh oblikah sklenitve zakonske zveze: confarreatio, coemptio, usus. Prvi dve obliki sta nujno vodili v zakonsko zvezo cum manu, druga pa le pod določenim pogojem. Posebej zanimiv je obstoj treh različnih oblik sklenitve, ki vodijo do načeloma enakih učinkov. Najpogostejša razlaga je, da je bila konfareacija prva oblika sklenitve zakonske zveze, saj so sprva le patriciji sklepali veljavno zakonsko zvezo, da je koempcija kasnejšega datuma in da je pravniški izum, da bi veljavno poroko omogočili tudi plebejcem in da se je usus razvil iz koempcije pa analogiji iz priposestvovanja $^{88,89}$. Druga razlaga vidi $\mathrm{v}$ koempciji ostanek starodavnega kupa žene, ki je bila skupna vsem Indoevropejcem, šele kasneje pa sta ji sledila konfareacija in usus. Tretja razlaga poskuša posamezne oblike sklenitve zakonske zveze povezati $z$ različnimi etničnimi elementi: konfareacija naj bi bila tako etruščanskega ali sabinskega izvora, koempcija in usus pa se pripisujeta zdaj Latincem, zdaj Etruščanom.

\section{1) CONFARREATIO}

Konfareacija je najbolj svečana in oblična oblika sklenitve zakonske zveze. Obredu so morali prisostvovati pontifex maximus, flamen Dialis in deseterica odraslih rimskih državljanov. Prav prisotnost svečenikov kaže na izrazit sakralni značaj te oblike sklenitve zakonske zveze. To je številne strokovnjake ${ }^{90}$ privedlo do sklepa, da je bila ta oblika sprva namenjena le patricijem.

${ }^{85}$ Genus enim est uxor; eius duae formae: una matrumfamilias, (eae sunt, quae in manum convenerunt;) altera earum, quae tantum modo uxores habentur (Cic. Top. 3, 14). Že v drugem stoletju beseda oznažuje le žensko dobrega znažaja.

${ }^{86}$ D. $50,1,1$.

${ }^{87}$ A. Romac: Rimsko pravo, IV. izdanje, Narodne novine, Zagreb 1992, p.111.

${ }^{88}$ Spekulacije o zgodovinskem razvoju povezemam v celoti po P.E.Corbett: The Roman Law of Marriage, Clarendon Press, Oxford, 1930 (reprint 1969), pp. 69-71.

${ }^{89}$ Priposestvovanje pomeni $v$ stvarnem pravu pridobitev lastninske pravice na stvari s samim potekom casa.

${ }^{90}$ Oscar Seyffert: The Dictionary of Classical Mythology, Religion, Literature and Art Gramercy Books, New York, 1901 (reprint 1995), p. 378, P.E.Corbett: The Roman Law of Marriage, Clarendon Press, Oxford, 1930 (reprint 1969), p. 75, A. Romac: Rimsko pravo, IV. izdanje, Narodne novine, 
Sklenitev zakonske zveze se je opravila "per quoddam genus sacrificii"; ženin in nevesta sta Jupitru (Iuppiter Farreus) darovala hlebček iz pire ${ }^{91}$ (panis farreus), ovco $^{92}$, sadje in slan kolać ${ }^{93}$ (mola salsa). Ženin in nevesta sta "capite velato" sedela na dveh zvezanih stolih, ki sta bila pokrita s kožo žrtvovane ovce ${ }^{94}$. Iz ohranjenih tekstov ni povsem jasno, ali sta morala določene obredne formule ${ }^{95}$ izgovoriti ženin in nevesta ali prisotni svečeniki. Prav lahko bi šlo za formule, $\mathrm{s}$ katerimi sta ženin in nevesta izrazila soglasje. Servij v komentarju k Eneidi ${ }^{96}$ govori tudi o tem, da naj bi se $v$ obredu uporabljala ogenj in voda kot dva poglavitna elementa. Varro ${ }^{97}$ omenja, da gre za izmenjavo vode in ognja med ženinom in nevesto, do katere je prišlo na pragu ženinovega doma. Izmenjava je bila po vsem sodeč del običaja, ki se je pogosto, ne pa obvezno, pojavljal pri vseh oblikah sklenitve zakonske zveze - in domum deductio. Prav tako je bilo del običaja postavljanje znanih vprašanj: ženin je nevesto vprašal "Quaenam vocaris?", ta pa mu je odgovorila: "Ubi tu Gaius, ego Gaia!"

Zapletenost obredov ${ }^{98}$ je kmalu povzročila, da je ta oblika skoraj povsem izginila. Že v Gajevem času (2.stol.n.št.) je bila izjemno redka, ohranila se je le zato, ker so bila nekatera svečeniška mesta dostopna le osebam, ki so bile rojene iz zakona, ki se je sklenil s konfareacijo, hkrati pa so se morali tudi sami poročiti na tak način. To so bili: flamines Diales, Martiales, Quirinales in pa rex sacrorum ${ }^{99}$.

\section{2) COEMPTIO}

Koempcija je prav tako privedla do zakona cum manu. Gre pravzaprav za fingirani $\operatorname{kup}^{100}$ : ženin navidezno kupi nevesto. Oblika koempcije je posneta po mancipaciji, pravnem poslu, s katerim se prenaša lastninska pravica na stvareh ${ }^{101}$. Tudi pri koempciji mora biti poleg strank prisotnih še pet prič (doraslih rimskih državljanov) in libripens, tehtničar, ki je v najstarejših časih, ko še ni bilo denarja, stehtal kupnino $\mathrm{v}$ bakru. Zastavlja se seveda vprašanje, kdo je nevesto prodal in komu je šla fiktivna kupnina - nummus unus ${ }^{102}$. Najbolj logično bi bilo sklepati, da novčič sprejme pater familias ali tutor, če je bila ženska sui iuris. Brez trdne podlage se zdi mnenje, da novčič sprejme nevesta sama ${ }^{103}$. To bi lahko pomenilo le, da je stranka v navidezni kupčiji ženska sama. Nepojasnjeno ostaja, kako bi lahko nevesta, ki je pod oblastjo družinskega očeta (pater familias), naenkrat sklepala tako pomemben pravni posel. Tudi če bi nevesta novčič sprejela, bi to pomenilo, da ga je pridobila za drugega: pred poroko za družinskega očeta, po poroki za moža. Konstrukcija torej ne vzdrži resne presoje.

\footnotetext{
91 Gai. 1,1 12 in Ulp., Reg., 9.

92 Servius, In Aen. 4,374.

93 Servius, In Georg. 1,31 "...per fruges et molam salsam coniungebantur...".

94 Servius, In Aen. 4,374.

95 Gaj govori o "sollemnia verba" (Gai. 1,112).

96 Servius, In Aen. 4,103 in 4,339.

97 Varro, De lingua Latina, 5,61

98 Tacit, Ann. 4,16 govori o caeremoniae difficultates, ki so poglavitni vzrok, da se ta oblika ne uporablja vec.

99 Gai. 1,112 .

$100 \mathrm{Gai}$ 1,113: "Coemptione vero in manum conveniunt per mancipationem, id est per quandam imaginariam venditionem...".

10! Bolj natanð̌neje na res mancipi (sužnji, domača vprežna in tovorna živina, italska zemljišča ter štiri poljske služnosti: iter, via, actus, aquaeductus).

102 P.E.Corbett: The Roman Law of Marriage, Clarendon Press, Oxford, 1930 (reprint 1969), pp. 81 sq.

103 Oscar Seyffert: The Dictionary of Classical Mythology, Religion, Literature and Art Gramercy

Books, New York, 1901 (reprint 1995), p. 378.
} 
Seveda so tudi to obliko poroke spremljali svečani obredi ${ }^{104}$, molitve in žrtvovanja $^{105}$. Boethius opisuje, kako je obred izgledal ${ }^{106}$ : "...et sese in coemendo invicem interrogabant, vir ita: an sibi mulier materfamilias esse vellet? Illa respondebat velle. Item mulier interrogabat: an vir sibi paterfamilias esse vellet? Ille respondebat velle...".

Koempcija je najbrž izginila okoli tretjega stoletja našega štetja.

\section{3) USUS}

Rimsko pravo je poznalo še eno obliko sklenitve zakona - usus. Zakonska zveza je tu nastala na povsem neformalen način, $z$ dejstvom skupnega življenja ${ }^{107}$. Tu je rimsko pravo pokazalo dobršno mero fleksibilnosti, saj se je v celoti ognilo formalizmom, ki so za antična prava tako značilni. Tudi usus se je oblikoval preko analogije $\mathrm{z}$ institutom stvarnega prava - priposestvovanjem. Priposestvovanje pomeni, da lahko stvar pridobimo s potekom določenega časa, če naše posesti te stvari nihče ne moti. Za priposestvovanje je $\mathrm{v}$ rimskem pravu veljalo: usus auctoritas fundi biennium est, - ceterarum rerum omnium - annuus est usus ${ }^{108}$. Vse stvari, z izjemo zemljišč, je bilo mogoče priposestvovati po preteku enega leta. Tako je tudi za zakonsko zvezo veljalo, da pridobi mož nad ženo manus, če traja skupno življenje neprekinjeno leto dni.

Žena pa se je imela možnost temu, da bi prišla pod moževo oblast, izogniti tako, da je vsako leto prebila tri dni (trinoctium abesse) ločeno od moža. Tako določbo je po Gajevih besedah vseboval že Zakonik XII plošč ${ }^{109}$.

Za sklenitev te zakonske zveze ni bilo potrebno opraviti formalnih obredov, še vedno pa so "poroko" obhajali na način, ki je bil običajen tudi za druge oblike zakonske zveze: opravili so običajne verske obrede, nevesto so privedli na možev dom (in domum deductio), naslednji dan je mož priredil zabavo, imenovana repotia. Poročni običaji so bili pomembni tudi iz pravnega vidika: le na ta način se je lahko določilo, kdaj se prične šteti leto dni, da pridobi mož manus nad ženo, šele od dne, ko so poroko obhajali, lahko štejemo, da obstaja maritalis affectio in da ne gre le za konkubinat $^{110}$. Od tega dne ima zakonska zveza vse pravne posledice zakonske zveze sine manu.

V klasični dobi (27 pr.n.št. - 300 n. št.) tridnevna odsotnost ženske ni bila več potrebna, da bi manus ne nastal. Poroka cum manu je bila tedaj že bolj izjema kot pravilo.

Že $v$ drugem stoletju našega štetja je usus večinoma opuščen, delno, kot pravi $\mathrm{Gaj}^{11 !}$, ker je bil odpravljen z zakonodajo, delno pa zaradi tega, ker ni bil pogosto uporabljan.

\footnotetext{
${ }^{104}$ Boethius, Topica, 3 "Coemptio vero certis sollemnitatibus peragebantur...".

105 Cic., De div. 1,16,28.

106 Boethius, Topica, 3.

${ }^{107}$ A. Romac: Rimsko pravo, IV. izdanje, Narodne novine, Zagreb 1992, p. 110.

${ }^{108}$ Cic. Top. 4,23 - pravilo baje izhaja iz VI. ploš̌e Zakonika XII plošc.

${ }^{109}$ Gai 1,111: Itaque lege XII tabularum cautum est, ut si qua nollet eo modo in manum mariti convenire, ea quotannis trinoctio abesset atque eo modo (usum) cuiusque anni interrumperet. ${ }^{110} \mathrm{Gl} . \mathrm{p} .2$ in op. 11.

II) Gai 1,111.
} 


\section{PRENEHANJE ZAKONSKE ZVEZE}

Zakonska zveza je po rimskem pravu prenehala zaradi (1) smrti, (2) capitis deminutio, (3) kot posledica obsodbe na določene kazni, (4) odsotnosti, (5) vpoklica v vojaško službo in končno (6) razveze zakonske zveze.

\section{1) SMRT ZAKONCA}

Zakonska zveza je s smrtjo enega od zakoncev prenehala. Drugi zakonec je bil načeloma prost in je lahko sklenil drugo zakonsko zvezo. Če je to pravilo brez izjeme veljalo za moškega, pa se je morala žena določeno dobo po smrti moža vzdržati poroke. Po klasičnem pravu je morala žena čakati devet mesecev, po postklasičnem pravu pa leto dni. To dobo so imenovali annus lugendi (leto žalovanja), čeprav je bil pravi namen te prepovedi predvsem to, da se ugotovi, če vdova ni morda noseča $z$ umrlim možem ${ }^{112}$. Če je žena pred koncem žalne dobe sklenila novo zakonsko zvezo, je bila ta sicer veljavna, zadele pa so jo druge neugodnosti. Značilen je trend poostritve sankcij: po civilnem pravu je morala manom pokojnega moža darovati brejo kravo (bovem fetam), po pretorskem pravu je zadela infamija njo in njenega očeta, če je bila pod njegovo oblastjo, po postklasičnem pravu pa so bile določene premoženjske kazni ${ }^{113}$.

\section{2) CAPITIS DEMINUTIO}

Če je zakonec izgubil prostost (capitis deminutio maxima), je to pomenilo, da je sklenjena zakonska zveza prenehala. Rimski državljan je lahko prostost izgubil le: - če ga je upnik prodal v suženjstvo (trans Tiberim);

- kadar je v republikanski dobi izostal od cenzusovega popisa;

- v primeru obsodbe za določena kazniva dejanja;

- če se je starejši od dvajsetih let dal prodati za sužnja, da bi dobil delež pri prigoljufani kupnini;

- če je padel v ujetništvo ${ }^{114}$.

Posebej zanimiv je primer rimskega državljana, ki je padel $\mathrm{v}$ ujetništvo. Posebej zanimiv zato, ker je rimsko pravo določalo, da so vse njegove pravice (res iuris) s trenutkom vrnitve na domače ozemlje zopet oživele (ius postliminium). Ker pa se je zakonska zveza štela za res facti, danes prevladuje mnenje, da zakonska zveza ni samodejno oživela, če je bil ujeti zakonec znova pridobil prostost ${ }^{115}$. Na temelju Pomponijevega odlomka ${ }^{116}$, ki se glasi: "Non ut pater filium, ita uxorem maritus iure postliminii recipit; sed consensu redintegratur matrimonium" je mogoče sklepati, da morata (bivša) zakonca zakonsko zvezo ponovno skleniti. Po Justinijanovem pravu je moral zakonec čakati pet let od takrat, ko je nastal dvom, ali je ujeti zakonec živ ali mrtev, da bi se lahko ponovno poročil.

Capitis deminutio media (izguba državljanstva) je imela za posledico, da je zakon prenehal biti veljaven po rimskem pravu (kot matrimonium iustum).

\section{3) OBSODBA NA NEKATERE KAZNI}

Določene kazni (servi poenae) so imele za posledico, da je obsojeni pridobil status sužnja: take kazni so bile obsodba na delo v rudnikih ( $a d$ metalla), obsodba na

${ }^{112}$ V. Korošec, Rimsko pravo, Il.del, Jože Moškric, Ljubljana, 1969, p.375.

113 Ibid. p. 376.

114 V. Koroß̌ec, Rimsko pravo, I.del, CZZ Uradni list RS, Ljubljana, 1991, pp.89 sq.

IIS P.E.Corbett: The Roman Law of Marriage, Clarendon Press, Oxford, 1930 (reprint 1969), pp. 214sq., enako npr. tudi A. Romac: Rimsko pravo, IV. izdanje, Narodne novine, Zagreb 1992, p. 113 ${ }^{316}$ D. $49,15,14,1$. 
boj $z$ divjimi živalmi v cirkusu (ad bestias) in obsodba na smrt (ad gladium). Logična posledica pravila, po katerem zakonska zveza preneha, če eden od zakoncev izgubi prostost (in postane suženj), je, da je imela obsodba za posledico prenehanje zakonske zveze.

Enak učinek sta imeli deportacija in pa aquae et ignis deportatio. V cesarstvu je krščanska ideja o nerazdružljivosti zakonske zveze imela za posledico, da so npr. deportacijo šteli le še kot priložnost (oz. razlog) za razvezo, obsodba in deportacija pa nista avtomatično pomenili prenehanja zakonske zveze ${ }^{117}$.

\section{4) ODSOTNOST}

Čeprav ta razlog ni vsestransko sprejet kot razlog za prenehanje zakonske zveze, je mogoče sklepati, da je zakonec v primeru daljše odsotnosti drugega zakonca in pod pogojem, da ni bil gotov, če je še živ, lahko ponovno sklenil zakonsko zvezo $^{118}$. Najbolj prepričljiv dokaz je odlomek iz Justinijanovega kodeksa ${ }^{119}$, v katerem Konstantin izraža mnenje, da se lahko žena, ki o možu v vojaški službi štiri leta ni prejela nobenih novic, znova poroči, če se brez uspeha obrne na moževega vojaškega poveljnika in ga obvesti o svoji nameri.

\section{5) VPOKLIC V VOJAŠKO SLUŽBO}

Cesarska zakonodaja je za čas vojaške službe izničila ali prekinila pravne učinke sklenjene zakonske zveze. To pravilo pa se glede častnikov ni upoštevalo že na začetku tretjega stoletja, popolnoma pa je izginilo v četrtem stoletju ${ }^{120}$.

\section{6) RAZVEZA ZAKONSKE ZVEZE}

Rimski viri ${ }^{121}$ so osupljivo skladni, ko poročajo, da je do prve razveze v Rimu prišlo celih petsto let po legendarni ustanovitvi Rima. Leta 231 pr.n.št. (če se opremo na Gelijevo verzijo), se je Spurij Karvilij, vir nobilis, ločil od žene, ki jo je sicer srčno ljubil, ker je bila neplodna (bolj natančno quia liberi ex ea corporis vitio non gignerentur). Pri tem se je skliceval na prisego, ki jo je moral izreči pred cenzorji, namreč, da vstopa $\mathrm{v}$ zakonsko zvezo $\mathrm{z}$ namenom prokreacije otrok (liberorum quaerundorum gratia).

Teza, da v Rimu ločitve pred tem niso poznali, je sporna. Ločitev (oz. enostransko odslovitev, repudiacijo) so poznale že družbe, ki so bile bistveno manj razvite kot rimska. Določbe o repudiaciji najdemo že $v$ Ur-nammujevem zakoniku (21. stoletje pr.n.št.) in Hamurabijevem zakoniku (18. stoletje pr.n.št.), slednji očitno pozna celo ločitev na ženino pobudo, s, seveda, za njo mnogo bolj neugodnimi posledicami. Oba določata predvsem obveznosti moža do žene. Še težje pa je $s$ Karvilijsko zgodbo uskladiti Plutarhovo poročanje o "krutem" Romulovem zakonu ${ }^{122}$. "Krutem" zato, ker ženi ni dopuščal razveze, mož pa je lahko ženo enostransko odslovil v primeru, da je zastrupila otroke ali v primeru prešuštva. Če pa bi do razveze prišlo iz kakšnih drugih razlogov, bi del njegovega premoženja pripadel ženi, del pa bi moral darovati Cereri. Končno je tu še Ciceronovo pričevanje ${ }^{123}$, da je že Zakonik XII

117 P.E.Corbett: The Roman Law of Marriage, Clarendon Press, Oxford, 1930 (reprint 1969), p. 211.

118 Ibid., p. 215.

119 C. $5,17,7$.

120 ibid., p. 217.

121 Aulus Gellius, Noctes Atticae 4,3; Dionisius. Antiq. 2,25; Plutarh Romulus,6, Numa, 3 in Quaestiones Romanae14; Valerius Maximus 2,1,4.

122 Plutarh Romulus, 22.

${ }^{123}$ Cic., Phil., 2,28,69: "Illam suas res sibi habere iussit, ex XII tabulis claves ademit, exegit." 
plošč poznal repudiacijo. Očitna neskladnost je pripeljala določene avtorje do tega, da so poskusili obe stališči uskladiti. Tako Karlowa ${ }^{124}$ meni, da gre pri Plutarhovem poročilu le za de facto ločitev, da torej ta ločitev nima pravnih posledic, Brini ${ }^{125}$ vidi $\checkmark$ Karvilijski razvezi razvezo zakonske zveze sine manu, Marquardt ${ }^{126}$ pa je zavzel stališče, da gre za prvi primer, ko je bila žena odslovljena brez krivde in brez sodbe, $v$ okoliščinah torej, ki so terjale vrnitev dote. Nobena od razlag se ne zdi posebej prepričljiva.

\section{a) RAZVEZA ZAKONSKE ZVEZE CUM MANU}

Rimsko pravo je poznalo dve temeljni obliki razveze zakonske zveze: diffarreatio in remancipatio. Difareacija je oblika razveze, ki se je uporabljala za razvezo zakonske zveze, ki je bila sklenjena s konfareacijo. $\mathrm{Z}$ gotovostjo lahko trdimo, da razveza ni bila dopustna za flamine ${ }^{127}$ vsaj do časa Domicijana ${ }^{128}$, od takrat pa le na posebno zahtevo.

Bolj negotova so mnenja nekaterih avtorjev, da je nerazvezljivost značilna za zakonske zveze, sklenjene s konfareacijo na splošno. Viri tega izrecno ne potrjujejo, Plutarh v Quaestiones Romanae ${ }^{129}$ izrecno navaja, da je razlog za prepoved razveze funkcija, ki jo flamines opravljajo. "Diffarreatio,". kot navaja Festus, "genus erat sacrificii, quo inter virum et mulierem fiebat dissolutio." Šlo je torej za nek svečan obred, v katerem so možu in ženi pred skupnim ognjiščem dali panis farreus, ki pa sta ga, namesto da bi si ga razdelila, kot je bilo to določeno pri konfareaciji, odvrgla, nato pa sta namesto molitev izrekla neke vrste prekletstva, s katerim se je žena odpovedala kultu svojega moža ${ }^{130}$. Plutarh ${ }^{131}$ govori v zvezi s difareacijo o "številnih grozljivih, neobičajnih in strašnih obredih".

Če torej sprejmemo stališče, da je bila že v zgodnjem Rimu zakonska zveza, sklenjena s konfareacijo, razvezljiva, velja to še toliko bolj za zakonske zveze, v katerih je mož pridobil manus s koempcijo ali s potekom leta dni v primeru usus-a. Oblika razveze je bila po splošnem mnenju $v$ teh dveh primerih remancipatio. $\mathrm{Za}$ koempcijo se to zdi umevno po pravilu nasprotne oblike (contrarius actus) za izničenje nekega pravnega posla. Vseeno se postavlja vprašanje, če ni bila razveza le pogoj za remancipacijo. Remancipacija je bila navidezna povratna prodaja žene njeni družini. Ženska se je zopet vrnila pod manus svojega očeta. Imela je torej le pravne učinke. Opomba Corbetta ${ }^{132}$, da je bil lahko učinek remancipacije v Gelijevem času le ta, da je spremenila zakon cum manu v zakon sine manu, se zato zdi utemeljena.

$\mathrm{Ob}$ razvezi (repudiaciji, bolj natančno) je bila značilna uporaba določenih besed: "Tuas res tibi habeto" ali "agito". Navajajo jih Cicero (Phil. 2,28,69), Plavt

\footnotetext{
124 Roemische Rechtsgeschichte, Leipzig, 1885-1901, p. 185, cit. po P.E.Corbett: The Roman Law of Marriage, Clarendon Press, Oxford,1930 (reprint 1969), p. 219.

125 Matrimonio e Divorzio nel Diritto Romano, Bologna 1887-9, p. 103, cit. po P.E.Corbett: The Roman Law of Marriage, Clarendon Press, Oxford, 1930 (reprint 1969), p. 219.

${ }^{126}$ Privatleben der Roemer, Leipzig, 1886, p. 69, cit. po P.E.Corbett: The Roman Law of Marriage, Clarendon Press, Oxford, 1930 (reprint 1969), p: 228 in Becker and Marquardt: Roman Private

Antiquities, cit. po Otto Kiefer: Sexual Life in Ancient Rome, Constable. London; 1994.

127 Aulus Gellius, Noctes Atticae 10,15,23.

128 Plutarh, Quaestiones Romanae, 50.

129 Ibidem.

130 Marko Mladenovic: Razvod braka i uzroci za razvod braka, Rad, Beograd, 1974, p.46.

$13 !$ Plutarh, Quaestiones Romanae, 50.

132 P.E.Corbett: The Roman Law of Marriage, Clarendon Press, Oxford, 1930 (reprint 1969), p. 223.
} 
(Amphitryo, 928), Marcijal (Ep. 10, 41) in Digeste $(24,2,2,1)^{133}$. "Formula" bržkone ni bila sakralne narave, drugače bi bilo spričo rigidnega rimskega formalizma težko pojasniti različne oblike, v katerih se pojavlja. V zadnjem stoletju republike uporaba te "formule" ni bila obvezna, vsaj v zakonski zvezi sine manu ${ }^{134}$.

Nekateri avtorji vidijo razliko $\mathrm{v}$ razvezi zakonske zveze cum manu in zakonske zveze sine manu tudi po tem, da je moral mož v prvem primeru zbrati amicorum consilium. To mnenje se opira na poročilo Valerija Maxima ${ }^{135}$, da je bil neki L. Anij izbrisan iz liste kandidatov za senat, ker se ni posvetoval s svetom prijateljev (amicorum consilium, morda gre za iudicium domesticum?), preden je odslovil svojo ženo. Na podlagi teh podatkov ni mogoče z gotovostjo trditi, da je bil postopek pred amicorum consilium obvezen in se manj, da je bila to differentia specifica med obema oblikama zakonske zveze.

\section{b) RAZVEZA ZAKONSKE ZVEZE SINE MANU}

$\mathrm{V}$ Ciceronovem času ni bilo jasno izoblikovane oblike razveze $\mathrm{v}$ primeru zakonske zveze sine manu ${ }^{136}$. Družinskopravna razmerja terjajo jasnost in preglednost, zato je Avgust v svoji Lex Julia de adulteriis vpeljal enotno obliko razveze $^{137}$. Po najbolj razšijeni razlagi je moral zakonec, ki je želel zakon razdreti, svojo voljo ustno izjaviti pred sedmimi pričami in pred svojim osvobojencem, ki je nato kot sel (nuntius) to sporočil drugemu zakoncu ${ }^{138}$. Corbett ${ }^{139}$ nadalje meni, da mora obstajati tudi resen namen doseči razvezo zakonske zveze. Forma sama po sebi ne zadostuje.

Pod vzhodnimi vplivi se je razvila pisna odslovitev (repudium) ${ }^{140}$. Zakonec, ki se je hotel ločiti, je moral drugemu poslati odslovilno pismo (libellus repudii). Cesarja Teodozij II. in Valentinijan III. ${ }^{141}$ sta 1.449 določila, da se mora razveza izvršiti misso repudio. Justinijan pa je obdržal tudi ločitev v obliki izjave pred sedmimi pričami.

Justinijan je razvezo 1.542 ponovno uredil $\vee 117$. noveli. Razveza je bila po tej ureditvi mogoča:

- iz utemeljenega razloga (ex iusta causa): gre za primere, ko enega od zakoncev zadeva neka krivda (veleizdaja, prešuštvovanje, streženje po življenju);

- v dobrem namenu (bona gratia): razvezo zahteva zakonec zaradi razlogov, ki so podani pri drugem zakoncu, četudi brez njegove krivde (nerodovitnost);

- sporazumno (communi consensu): sporazumno razvezo je Justinijan načeloma prepovedal, dovoljena je le, če naj omogoči, da odide eden od zakoncev v samostan;

- brez utemeljenega razloga (sine iusta causa): razveza, izvršena brez utemeljenega razloga ni nična, je pa kazniva.

${ }^{133}$ vsi navedki citirani po P.E.Corbett: The Roman Law of Marriage, Clarendon Press, Oxford, 1930 (reprint 1969), p. 224.

134 Ibidem, p.224.

135 Val. Max. Memorabilia, 2,9,2.

${ }_{136}^{136}$ P.E.Corbett: The Roman Law of Marriage, Clarendon Press, Oxford, 1930 (reprint 1969), p. 228.

${ }_{137}$ Nullum divortium ratum est, nisi septem civibus Romanis puberibus adhibitis praeter libertum eius qui divortium faciet (D. 24,2,9).

${ }_{138}^{138}$ V. Korošec, Rimsko pravo, II. del, Jože Moškrǐ, Ljubljana, 1969, p.377.

139 P.E.Corbett: The Roman Law of Marriage, Clarendon Press, Oxford,1930 (reprint 1969), p. 233.

140 V. Korosec, Rimsko pravo, Il.del, Jože Moskrǐ, Ljubljana, 1969, p. 377, P.E.Corbett: The Roman Law of Marriage, Clarendon Press, Oxford,1930 (reprint 1969), p. 236.

${ }^{141}$ C. $5,17,8$ pr. 


\section{c) SPOSOBNOST IN POGOJI}

Vse do Antoninov je pater familias lahko razdrl zakonsko zvezo (cum ali sine manu) svojega sina in zakonsko zvezo sine manu svoje hčere ( $\mathrm{z}$ interdiktom de liberis exhibendis et ducendis) ne glede na njuno voljo. Ce sodimo po odlomku Paulovih Sentenc $^{142}$, je šele Antonin Pij omejil to očetovo pravico, pa še to le glede složnih zakonov (bene concordans matrimonium). Tudi Justinijan pa je priznaval ženinemu očetu pravico, da razdre zakon, če je obstajal resen razlog za ločitev ${ }^{143}$.

Žena sprva ni mogla doseči razveze v zakonski zvezi cum manu. V zakonski zvezi sine manu sta bila oba partnerja enakopravna najkasneje ob koncu 3. stoletja pr.n.št ${ }^{144}$, lahko pa da že od samega začetka. Da so imele osebe alieni iuris pravico do razveze zakonske zveze ne glede na mnenje družinskega očeta (pater familias) že pred Justinijanom, nam morda najjasneje dokazuje obiter dictum iz C. 5,17,12: "liberis vero ... praeter patrum voluntatem matrimonium solvere et inde patres iniuria adficere".

Vsekakor si lahko zastavimo vprašanje, kako je lahko sin, ki je bil in potestate svojega družinskega očeta (pater familias), sam izvršil remancipacijo za svojo ženo, ki je bila, formalno gledano, pod oblastjo njegovega družinskega očeta ${ }^{145}$. Če je bila torej remancipacija nujen pogoj za ločitev, se zdi, da se je težko izogniti takšni ali drugačni intervenciji moževega družinskega očeta. Kot alternativno razlago je mogoče sprejeti le tezo, da je razveza (repudiacija s strani enega ali drugega zakonca) imela stvarni učinek prenehanja zakonske zveze (razvezana žena pa je de iure ostala del moževe družine), remancipacija pa je imela pravne učinke in je imela za posledico, da je bila razvezana žena izključena iz moževe družine.

\section{d) OMEJITVE PRAVICE DO RAZVEZE}

Krščanski cesarji so pričeli sčasoma omejevati pravico do razveze. Konstantin je prepovedal objestne repudiacije ${ }^{146}$. Pijanstvo, kvartopirstvo in prešuštvo niso razlogi, zaradi katerih bi se žena lahko ločila od moža. Takšna razveza pa ni nična, pač pa žena izgubi doto, donationes ante nuptias, obsojena je lahko tudi na deportacijo. Mož lahko zahteva ločitev zaradi prešuštva, zvodništva ali če ugotovi, da ga želi žena zastrupiti. Kazen je izguba dote in daril, ki jih je prejel pred sklenitvijo zakonske zveze (donationes ante nuptias).

Honorijev, Teodozijev in Konstantinov zakon iz $421 \mathrm{n}$.št. je spremenil kazni. Deportacija grozi ženi le, če ne more dokazati morum vitia ac mediocres culpas. Če se ji dokaz posreči, jo doleti le izguba dote, daril, ki jih je prejela pred sklenitvijo zakonske zveze in prepoved ponovne poroke. Mož se lahko loči od žene, ki je obsojena za težak zločin.

Codex Iustinianus $(5,17,8)$ povzema razloge, ki opravičujejo ločitev. Če se žena razveže iz razloga, ki ni zakonsko dopusten, jo lahko doleti tudi prepoved poroke za dobo pet let (suspenz konubija). Leta 528. doda Justinijan seznamu moževo impotenco kot razvezni razlog, 1.533 pa splav in nameravano prešuštvo kot razloga za razvezo na ženini strani. V 117 . noveli je Justinijan dokončno uredil razvezo ${ }^{147}$.

${ }^{142}$ Paul. Sent. 5,7,15.

143 C. $5,17,5$.

144 P.E.Corbett: The Roman Law of Marriage, Clarendon Press, Oxford, 1930 (reprint 1969), p. 242.

i45 Ibidem, p. 241.

146 Ibidem, p.244.

${ }^{147}$ Gl. stran 19. 


\section{SUMMARY}

The author's intent is to present a clear and accurate a survey of legal regulation regarding marriage in Roman law. First, the author deals with certain preconditions, which had to be met in order a marriage could at all take place: conubium, maturity and consensus (of both partners and their patres familias). The first step towards marriage was sponsalia - betrothal, which had (unlike today) certain legal consequences. In Roman law there were two types of marriage: marriage cum manu and sine mamu, the main difference being in wife's legal status. In marriage cum manu wife came under the manus of her husband, whereas in marriage sine manu her father kept manus over her. The author then briefly describes confareatio, coemptio and usus, three basic forms of marriage which had to be observed in order a lawful marriage to be constituted. At the end the author discusses the question of dissolution of marriage (divorce, death, deportation, captivity). 